\title{
Understanding abiotic ferrihydrite re-mineralization by ferrous ions
}

\author{
M. Raghav $•$ A. E. Sáez $\cdot$ W. P. Ela
}

Received: 26 February 2013/Revised: 15 March 2014/Accepted: 21 April 2014/Published online: 7 May 2014

(C) Islamic Azad University (IAU) 2014

\begin{abstract}
In this work, we study the abiotic re-mineralization of ferrihydrite under reducing conditions, obtained by adding zero-valent iron (ZVI) to a suspension of ferrihydrite particles. Under similar conditions, the system (ferrihydrite and ZVI) proceeded along two different transformation pathways differentiated by whether a magnetic stirrer or an overhead stirrer was used for mixing. X-ray diffraction characterization of the solid products showed that magnetite was the sole product of ferrihydrite transformation when a magnetic stirrer was used, whereas both goethite and magnetite were formed when an overhead stirrer was used. The system also behaved differently in terms of transformation kinetics and amount of magnetite formed. The quantification of magnetite generated was performed using a procedure developed in this study. The role of four mechanisms was investigated to explain these observed differences, namely-(1) presence/absence of high local $\mathrm{Fe}^{2+}$ concentrations, (2) mechanical abrasion, (3) presence/absence of a magnetic field, and (4) presence/ absence of a crystalline ZVI surface. Ferrous ions are expected to be concentrated near the magnetic bead on the magnetic stirrer as opposed to a more dispersed distribution with the overhead stirrer. This mechanistic study concluded that the presence of high local $\mathrm{Fe}^{2+}$ concentrations in the system leads to magnetite formation and the absence of the same leads to mixed goethite/magnetite or magnetite-free systems. These findings have significant implications for the mobilization of arsenic from iron (III) hydroxides as the conditions move from oxidizing to reducing, such as often
\end{abstract}

M. Raghav · A. E. Sáez · W. P. Ela (ه)

Department of Chemical and Environmental Engineering, The

University of Arizona, Tucson, AZ 85721, USA

e-mail:wela@email.arizona.edu occurs in engineered landfills and natural carbon-rich sediments.

Keywords Arsenic - Iron compounds - Phase transformation $\cdot$ Water treatment $\cdot$ Landfills

\section{Introduction}

Under oxidizing conditions, iron(III) (hydr)oxide minerals play a key role in the solid sequestration of contaminants such as arsenic in the natural environment as well as in treatment systems for removing arsenic from water (e.g., Smedley and Kinniburgh 2002; Datta et al. 2009; Giles et al. 2011; Omoregie et al. 2013; Shan et al. 2013). It is also well established that the iron (III)(hydr)oxide system is redox sensitive; one iron oxide transforming into another depending on various conditions such as $\mathrm{pH}$, temperature, presence of ferrous ions, anions such as chloride, sulfate, and oxyanions such as arsenic (Liu et al. 2005, 2008a; Pedersen et al. 2005; Yee et al. 2006; Mukiibi et al. 2008; Das et al. 2011a, 2011b). In natural and engineered environments, reductive dissolution of the ferric minerals is commonly cited as a primary mechanism causing arsenic mobilization (Pedersen et al. 2006; Ghosh et al. 2006; Jing et al. 2008; Nguyen and Itoi 2009; Borch et al. 2010; Halim et al. 2010; Burnol and Charlet 2010; Maity et al. 2011). However, the degree of iron mobilization often does not correlate well with the degree of arsenic release (Islam et al. 2004; Horneman et al. 2004; Burnol et al. 2007; van Geen et al. 2006; Kocar et al. 2006; Ghosh et al. 2006; Borch et al. 2010; Reza et al. 2010). This decoupling of iron and arsenic release into the aqueous phase has been linked to the formation of secondary iron minerals with reduced arsenic adsorption capacity (Pedersen et al. 2006; 
Kocar et al. 2006; Tufano and Fendorf 2008; Borch et al. 2010; Reza et al. 2010). For instance, typical specific surface area of ferrihydrite $\left(600 \mathrm{~m}^{2} \mathrm{~g}^{-1}\right)$ is higher than that of its transformation products, goethite and magnetite (54 and $90 \mathrm{~m}^{2} \mathrm{~g}^{-1}$, respectively) (Dixit and Hering 2003). Maximum sorbed concentrations of arsenite at $\mathrm{pH} 8$ on goethite and magnetite are much lower (173 \pm 13 and $332 \pm 30 \mu \mathrm{mol} \mathrm{g}{ }^{-1}$, respectively) than on ferrihydrite $\left(3,514 \pm 157 \mu \mathrm{mol} \mathrm{g}^{-1}\right)$ (Dixit and Hering 2003). On the other hand, Mamindy-Pajany et al. (2011) reported adsorption capacities of 1.4 and $5.4 \mu \mathrm{mol} \mathrm{m}{ }^{-2}$ for $\mathrm{As}(\mathrm{V})$ on commercial goethite $\left(11.61 \pm 0.19 \mathrm{~m}^{2} / \mathrm{g}\right)$ and magnetite $\left(1.60 \pm 0.01 \mathrm{~m}^{2} / \mathrm{g}\right)$, respectively. It is, therefore, important to understand the mineralogical transformations that iron(III) (hydr)oxides undergo to ascertain the degree to which these transformations will subsequently impact the sequestration of the arsenic.

Magnetite $\left(\mathrm{Fe}_{3} \mathrm{O}_{4}\right)$ is commonly observed to form from iron(III) (hydr)oxide minerals, such as natural sediments and commercial arsenic water treatment sorbents in the presence of iron-reducing bacteria, when conditions transition from aerobic to anoxic (Liu et al. 2008b; Borch et al. 2010; O'Loughlin et al. 2010; Zegeye et al. 2010; Neumann et al. 2013). As a mixed-valent iron oxide, magnetite is an intermediate phase between the aerobically stable Fe(III) (hydr)oxides and the anaerobically stable Fe(II) sulfides and oxides/hydroxides. Goethite is a crystalline Fe(III) oxy-hydroxide that is known to form as a transformation product of ferrihydrite (Cornell and Schwertmann 2003). Several studies have shown that the presence of ferrous ions catalyzes this transformation (Benner et al. 2002; Pedersen et al. 2005; Hansel et al. 2003, 2005; Yang et al. 2010).

Physical heterogeneity within soils is known to give rise to localized biogeochemical gradients due to the presence of both advection (in large pores) and diffusion (in smaller micropores)-dominated domains (Tufano et al. 2009; Pallud et al. 2010; Masue-Slowey et al. 2013). The localized buildup of $\mathrm{Fe}^{2+}$ due to $\mathrm{Fe}$ (III) reduction is hence common in heterogeneous systems such as landfills. Aqueous $\mathrm{Fe}^{2+}$ concentration is an important parameter influencing the transformation of ferrihydrite to secondary Fe minerals and hence sequestration and release of contaminants like arsenic (Pedersen et al. 2005; Hansel et al. 2003; 2005; Latta et al. 2012).

The objective of this paper was (1) to understand the different transformation pathways/products of ferrihydrite under the presence or absence of locally high $\mathrm{Fe}^{2+}$ concentrations and (2) to gain insights into the implications of such transformations for the sequestration/release of arsenic associated with iron-based water treatment residuals under landfill conditions. It should be mentioned that the goal here was not to develop a remedial process for the stabilization of arsenic in the water treatment residuals, but to interrogate the factors causing an iron-rich oxic system to generate different secondary minerals when it transitions into a reducing system and, consequently, have greater or lesser arsenic retention capacity. This study was conducted from May 2008 to May 2010 in the Environmental Engineering labs at the University of Arizona, Tucson.

\section{Materials and methods}

Preparation of synthetic ferrihydrite

Synthetic ferrihydrite was prepared based on a modified procedure for ferrihydrite synthesis reported by Mukiibi et al. (2008). One liter of $1 \mathrm{M}$ anhydrous ferric chloride solution was titrated with $10 \mathrm{M} \mathrm{NaOH}$ to a $\mathrm{pH}$ of 7.0 within $1 \mathrm{~h}$. The $\mathrm{pH}$ was brought up to 7 to mimic the arsenic removal process using coagulation, co-precipitation, and adsorption on ferric hydroxide in water treatment facilities. It has been reported that the best arsenic removal is achieved at $\mathrm{pH}$ values $<7.2-7.5$ (Jekel and Amy 2006). The suspension was allowed to settle and equilibrate for $48 \mathrm{~h}$, until the $\mathrm{pH}$ stabilized at 7.0. The $\mathrm{pH}$ fluctuated by \pm 0.3 during this period and was adjusted back to 7 as necessary using $0.1 \mathrm{M} \mathrm{HCl}$ or $0.1 \mathrm{M} \mathrm{NaOH}$. The $\mathrm{pH}$ of the suspension was monitored for $48 \mathrm{~h}$ to ensure that the $\mathrm{pH}$ had stabilized at 7.0. The precipitate was then vacuum filtered using $0.22 \mu \mathrm{m}$ membrane filters to achieve a water content of approximately $75 \mathrm{wt} \%$ and rinsed multiple times with deionized water to remove residual salts. The whole procedure was carried out at room temperature. The solid was transferred to high-density polyethylene storage jars, sealed tightly using parafilm, and stored at $4{ }^{\circ} \mathrm{C}$ for later use.

Synthetic arsenic-bearing solid residuals (ABSRs) were also produced to study the effect of arsenic's presence on ferrihydrite transformations. The synthesis procedure used was similar to the procedure described above except that sodium arsenate solution was added to the Fe(III) solution before the $\mathrm{pH}$ was brought up to 7 . Three different solids with Fe/As molar ratio of 5.7, 20, and 100 were synthesized.

The total iron and arsenic content of the synthesized solids was determined by microwave digestion of known amounts of the solids. Solid samples of $0.5 \mathrm{~g}$ (wet weight) were weighed and digested in $14.5 \mathrm{~mL}$ of concentrated nitric acid for 20 min using a CEM MDS 2100 Microwave Digestion System. Five replicates were run in each case. Digested samples were diluted and analyzed for iron content using the phenanthroline test (Clesceri et al. 1998) and for arsenic content using an ion coupled plasma mass spectrometer (ICPMS, Agilent 7500a). 
Deoxygenated water used in this study was prepared by heating deionized water in a 2-L conical flask to $90 \pm 4{ }^{\circ} \mathrm{C}$ for $1 \mathrm{~h}$, while bubbling nitrogen in the headspace. The flask was then sealed tightly, stored inside a Terra Universal Critical Environment Solutions glove box purged with nitrogen at room temperature $\left(20-25^{\circ} \mathrm{C}\right)$, and the water used as needed.

\section{Experimental system}

Batch experiments were conducted using the synthesized ferrihydrite and zero-valent iron (ZVI) as the reducing agent. Analytical grade ZVI (200 mesh, 99+ \% purity on metals basis) was used as purchased (Alfa Aesar). All the experiments were performed inside the glove box. The synthesized ferrihydrite solid was used to prepare a suspension containing $0.3 \mathrm{~g}$ of $\mathrm{Fe}(\mathrm{III})$ in $100 \mathrm{~mL}$ of deoxygenated water. The initial $\mathrm{pH}$ was $6.8 \pm 0.2$ in all the experiments. The system was continuously stirred using an overhead stirrer, a magnetic stirrer or an overhead stirrer with a magnetic stir bar attached (at $300 \mathrm{rpm}$ in all cases) as dictated by the specific trial objective (described later). Individual batches were killed at time intervals of $16 \mathrm{~h}$, 3 days, or 10 days. In one set of trials, a measured amount of ZVI was added to the solution in order to achieve an initial $1: 1$ ratio of $\mathrm{Fe}^{3+}: \mathrm{Fe}^{0}$ in the system. In a second set of trials, $\mathrm{Fe}^{2+}$ was added directly in lieu of ZVI. In these cases, $0.3 \mathrm{~g}$ of the ferrihydrite solid as $\mathrm{Fe}^{3+}$ was added to $20 \mathrm{~mL}$ of deoxygenized water and homogenized on a magnetic stir plate for half an hour before addition of the $\mathrm{Fe}^{2+}$. The initial $\mathrm{pH}$ of this solution was $6.8 \pm 0.2$, similar to the experiments conducted with ZVI.

Trials using direct injection of $\mathrm{Fe}^{2+}$ (added as ferrous sulfate) used one of two rates for addition-a fast rate of $30.6 \mathrm{mg}$ of $\mathrm{Fe}^{2+} / \mathrm{hr}$ for $5 \mathrm{~h}$ to mimic the fastest rate of $\mathrm{Fe}^{2+}$ generation observed in the experiments with ZVI, and a slower rate of $3.1 \mathrm{mg}$ of $\mathrm{Fe}^{2+} / \mathrm{hr}$ for 4 days to mimic the average slow rate of $\mathrm{Fe}^{2+}$ generation observed in the experiments with ZVI ("Results and discussion" section). Ferrous sulfate solutions of concentrations 0.0342 and $0.0670 \mathrm{M}$ were used for the fast and slow rate experiments, respectively, in order to bring the final volume of the batch to $100 \mathrm{~mL}$. In the case of the experiments with the fast rate of $\mathrm{Fe}^{2+}$ addition, the $\mathrm{pH}$ was maintained at $6.8 \pm 0.2$ by adding $0.3 \mathrm{M} \mathrm{NaOH}$, as needed. This was done to mimic $\mathrm{pH}$ trends in the system employing the magnetic stirrer with ZVI added as the source of $\mathrm{Fe}^{2+}$, where the $\mathrm{pH}$ was nearly constant at 6.8 (results not shown). In case of the experiments with slow rate of $\mathrm{Fe}^{2+}$ addition, no $\mathrm{pH}$ adjustment was made and the $\mathrm{pH}$ was observed to decrease to 4.2 and rise up to $\approx 5.8$ at the end of 4 days. This was done to mimic $\mathrm{pH}$ trends in the system employing the overhead stirrer with ZVI added as the source of $\mathrm{Fe}^{2+}$ (results not shown).

Experiments were also conducted with arsenic added in order to study the effect of arsenic on ferrihydrite transformations in the presence of high local $\mathrm{Fe}^{2+}$ concentrations. Transformations of the three iron-arsenic solids (Fe/ As molar ratio $=5.7,20$ and 100) were studied by performing experiments analogous to the ones performed with the ferrihydrite solid, at an initial $\mathrm{pH}$ of $6.8 \pm 0.2$ and initial $\mathrm{Fe}^{3+}$ : ZVI ratio of $1: 1$.

\section{Solids characterization}

Solid samples for X-ray diffraction (XRD) were collected by filtering approximately $100 \mathrm{~mL}$ of solution through a $0.22-\mu \mathrm{m}$ filter and rinsing the solid on the filter multiple times with deoxygenated water. The solids were then dried inside the glove box purged with nitrogen. All the steps were carried out inside the glove box, and the dried solids were collected in tightly sealed vials and stored inside the glove box until taken out for solid characterization.

The crystalline phases in the bulk samples were identified using XRD patterns collected on a Bruker D8 ADVANCE diffractometer using $\mathrm{CuK \alpha}$ radiation. The samples were scanned from $5^{\circ}$ to $90^{\circ}$ for over $285 \mathrm{~min}$, and diffraction patterns were recorded. Patterns were matched against those in the International Centre for Diffraction Data (ICDD) database.

\section{ZVI-magnetite quantification}

A method was developed as part of this study for the quantitative analysis of magnetite generated and ZVI remaining in the system at the end of each experiment. This method is somewhat analogous to that used for the determination of chemical oxygen demand (COD).

Step 1 Dissolution of magnetite and ZVI by concentrated sulfuric acid.

A weighed mass of the magnetic fraction (residual ZVI and magnetite) collected at the end of an experiment was added to $100 \mathrm{~mL}$ of deoxygenated water in an Erlenmeyer flask. The flask's top was connected to a vertical glass column-containing water; $200 \mathrm{~mL}$ of 9-M sulfuric acid was added to the solution and allowed to react for $45 \mathrm{~min}$. During preliminary method development trials, this was determined to be sufficient time to dissolve all the solids for the maximum total weight of solids expected if all the ferrihydrite transformed to magnetite. By measuring the displacement of the water level in the glass column, the volume of hydrogen generated in the reaction was determined. 
Step 2 Oxidation of reduced iron in solution by potassium dichromate.

After $45 \mathrm{~min}$, an excess (2 times the stoichiometric demand, assuming all the remaining solid was ZVI) of potassium dichromate was added to oxidize all the reduced iron in the system. After $20 \mathrm{~min}$, a $2-\mathrm{mL}$ aqueous sample was taken. The aqueous sample was diluted immediately and analyzed for total iron.

Step 3 Addition of ferrous sulfate to reduce the residual potassium dichromate.

Following step 2, excess ferrous sulfate was added to the solution. A 2-mL aqueous sample was taken after $1 \mathrm{~h}$, diluted and analyzed for $\mathrm{Fe}(\mathrm{II})$ concentrations using the phenanthroline method.

The amount of ferrous sulfate oxidized by potassium dichromate allowed for the determination of the amount of potassium dichromate consumed in step 1 to oxidize all the reduced iron in magnetite and ZVI.

The moles of electrons that must be withdrawn to fully oxidize all reduced iron in the system $\left(\mathrm{TOTe}^{-}\right)$and the total number of moles of iron (TOTFe) from both magnetite and ZVI are given by

$N_{m}+3 N_{z}=$ TOTe

$3 N_{m}+N_{z}=$ TOTFe

where $\mathrm{N}_{\mathrm{m}}$ and $\mathrm{N}_{\mathrm{z}}$ are the number of moles of magnetite and ZVI, respectively.

$\mathrm{TOTe}^{-}$is calculated as the number of electrons transferred from dichromate to oxidize all the remaining reduced iron to $\mathrm{Fe}^{3+}$ and generate hydrogen by the reaction of the ZVI with sulfuric acid (procedure detailed below),

$2 \mathrm{Fe}^{0}+\mathrm{Cr}_{2} \mathrm{O}_{7}^{2-}+14 \mathrm{H}^{+} \rightarrow 2 \mathrm{Fe}^{3+}+2 \mathrm{Cr}^{3+}+7 \mathrm{H}_{2} \mathrm{O}$

$6 \mathrm{Fe}^{2+}+\mathrm{Cr}_{2} \mathrm{O}_{7}^{2-}+14 \mathrm{H}^{+} \rightarrow 6 \mathrm{Fe}^{3+}+2 \mathrm{Cr}^{3+}+7 \mathrm{H}_{2} \mathrm{O}$

$2 \mathrm{Fe}^{0}+6 \mathrm{H}^{+} \rightarrow 2 \mathrm{Fe}^{3+}+3 \mathrm{H}_{2}$.

Ferrihydrite is not detected by XRD owing to its amorphous nature, so in all trials the possibility existed that some untransformed ferrihydrite could remain at the end of the experiment. Both magnetite and ZVI were separated from any nonmagnetic solid species by collection on a Teflon-coated magnetic bead. The process was repeated using a fresh magnetic bead to confirm that the magnetic fraction remaining in the suspension after this point was insignificant. A similar technique for separation and recovery of magnetic minerals has been employed by Horneman et al. (2004). The magnetic bead with the magnetite and ZVI was recovered and directly used in the ZVI-magnetite quantification procedure.
For validation purposes, known amounts of magnetite and ZVI were mixed and analyzed using the procedure described above. Magnetite was synthesized based on the standard procedure in Schwertmann and Cornell (1991) via partial oxidation of ferrous chloride solution. The magnetite thus synthesized and pure ZVI were mixed at different ratios (Magnetite/Total weight $=0-1$ ) with at least 3 replicates of each ratio.

Student's $t$ test was performed on the data set, and the results were found to be statistically significant at the $95 \%$ confidence interval (not shown here).

\section{Results and discussion}

Baseline experiments to characterize ferrihydrite transformation products were conducted using a magnetic stirrer or an overhead stirrer with ZVI addition, keeping all other conditions constant. Solid samples collected after 10 days from the magnetic stirrer were black in color for the magnetic stirrer system (indicative of magnetite), and from the overhead stirrer system they were yellowish green (indicative of goethite and/or green rust). The XRD spectra of solids from the magnetic stirrer system (Fig. 1) showed that magnetite and residual ZVI were the only crystalline phases. Magnetic fraction separation showed that the nonmagnetic fraction remaining in the solid was insignificant. In the overhead stirrer system, the product consisted of a mixture of goethite, magnetite, and residual ZVI (Fig. 2).

Four possible mechanisms were considered to explain the different transformation products observed in the magnetic and overhead stirrer trials-(1) $\mathrm{Fe}^{2+}$ concentration levels near the solid surface, (2) abrasion and grinding,

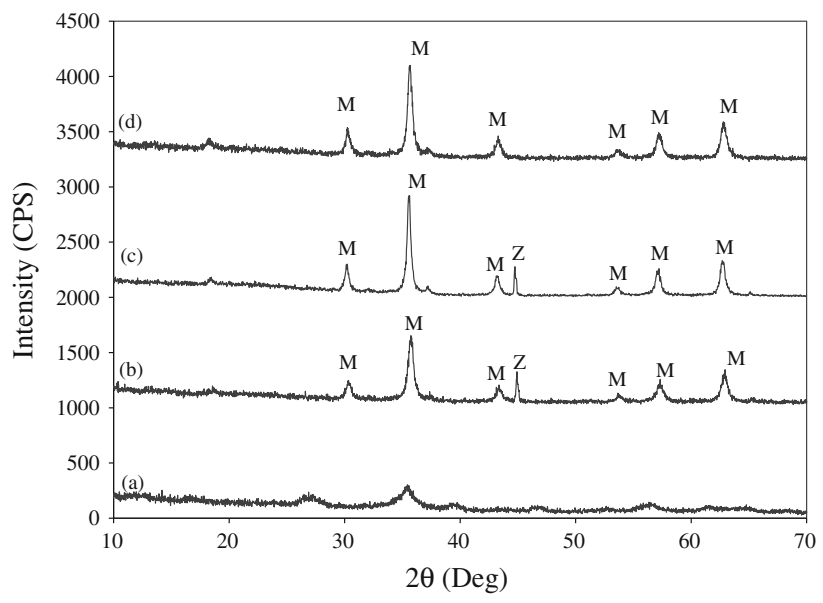

Fig. 1 XRD spectra for product solid taken $(a)$ initially, $(b)$ after $5 \mathrm{~h}$, $(c)$ after $16 \mathrm{~h}$, and $(d)$ after 10 days. All experiments were performed using a magnetic stirrer with initial $\mathrm{Fe}^{3+}$ :ZVI ratio of 1.0 and $\mathrm{pH}$ $6.8 \pm 0.2$. $M$ magnetite, $Z \mathrm{ZVI}$ 


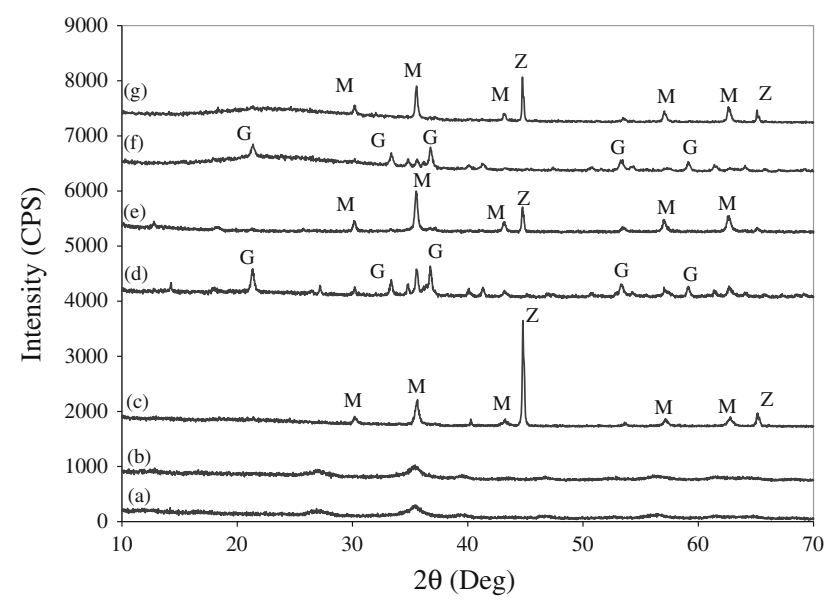

Fig. 2 XRD spectra for product solid taken $(a)$ initially, $(b)$ after $16 \mathrm{~h}$, nonmagnetic fraction, $(c)$ after $16 \mathrm{~h}$, magnetic fraction, $(d)$ after 3 days, nonmagnetic fraction, (e) after 3 days, magnetic fraction, $(f)$ after 10 days, nonmagnetic fraction, and $(g)$ after 10 days, magnetic fraction. All experiments were performed using an overhead stirrer with initial ferrihydrite:ZVI ratio of 1.0 and $\mathrm{pH} 6.8 \pm 0.2$. $M$ magnetite, $Z \mathrm{ZVI}, G$ goethite

(3) presence or absence of a magnetic field, and (4) presence or absence of a ZVI surface. Initially, ZVI oxidation is the only source of $\mathrm{Fe}^{2+}$ in both systems. However, $\mathrm{Fe}^{2+}$ generation is locally concentrated on the stir bar to which ZVI particles adhere in the magnetic stirrer case, as opposed to the overhead stirrer case where the $\mathrm{Fe}^{2+}$ generation is distributed throughout the reactor volume since ZVI particles are completely dispersed. In what follows, we analyze possible effects of each mechanism.

The role of $\mathrm{Fe}^{2+}$ as a catalyst in accelerating the transformation of ferrihydrite to various iron oxide minerals including goethite and magnetite has been discussed extensively in the literature (Benner et al. 2002; Hansel et al. 2003; Pedersen et al. 2005; Hansel et al. 2005; Yee et al. 2006; Yang et al. 2010). Pedersen et al. (2006) concluded that iron(III) (hydr)oxides undergo phase transition to more stable phases due to the catalytic action of $\mathrm{Fe}^{2+}$ adsorbed on the surface. They explained that the adsorbed $\mathrm{Fe}^{2+}$ exchanged for $\mathrm{Fe}(\mathrm{III})$ in terminal octahedral positions. The $\mathrm{Fe}(\mathrm{II})-\mathrm{O}$ bond being more labile than the $\mathrm{Fe}(\mathrm{III})-\mathrm{O}$ bond caused the crystal structure to disintegrate resulting in the dissolution of ferrihydrite followed by reprecipitation of more stable phases like goethite by Ostwald ripening.

On the other hand, Fe(II) sorption also drives solid-state conversion of ferrihydrite to magnetite (Cornell 1988; Tronc et al. 1992). In column experiments using ferrihydrite-coated sands, a direct correlation has been observed between $\mathrm{Fe}(\mathrm{II})$ concentrations and the solid phases present, both temporally and spatially (Hansel et al. 2003; Benner et al. 2002). Hansel et al. demonstrated that both the $\mathrm{Fe}^{2+}$ generation rate and flow-induced $\mathrm{Fe}^{2+}$ concentration profiles play an important role in determining the transformation products of ferrihydrite. Goethite precipitated at the influent end of the column where $\mathrm{Fe}^{2+}$ concentrations were low, whereas magnetite formed under the presence of the high $\mathrm{Fe}^{2+}$ concentrations present near the effluent end of the column.

In another study by Tufano et al. (2009), it was established that gradients in $\mathrm{Fe}^{2+}$ concentrations in diffusioncontrolled systems might result in spatial patterns that lead to varied secondary mineral formation. In their experiments, magnetite and green rust formed at the inlet of a pore where the $\mathrm{Fe}^{2+}$ concentrations were high. At increasing distances from the pore entrance where lower $\mathrm{Fe}^{2+}$ concentrations exist, goethite was the predominant phase.

In our system when the magnetic stir plate is used, high local $\mathrm{Fe}^{2+}$ concentrations exist near the magnetic bead due to the accumulation of ZVI particles in that region. This is in contrast to the more dispersed generation of $\mathrm{Fe}^{2+}$ in the case of the overhead stirrer. Hence, the ferrihydrite in the magnetically stirred system is exposed to high concentrations of $\mathrm{Fe}^{2+}$ and transformation to magnetite is favored over dissolution-re-precipitation of ferrihydrite to goethite.

These results are consistent with those found by Yang et al. (2010) in a recent study of the kinetics of Fe(II)catalyzed transformation of 6-line ferrihydrite under anaerobic flow conditions. They reported that at a concentration of $0.36 \mathrm{mM} \mathrm{Fe}^{2+}$, goethite was the major phase formed as a result of ferrihydrite transformation, with minor amounts of magnetite being detected. At higher concentrations of 1.8 and $18 \mathrm{mM} \mathrm{Fe}^{2+}$, magnetite was the only secondary phase that formed. This was described as being due to the presence of higher electron current density when high $\mathrm{Fe}^{2+}$ concentrations were present, which allows for rapid internal structural rearrangement of the ferrihydrite particles to form magnetite nuclei. In the case of low $\mathrm{Fe}^{2+}$ concentrations, the electron current density is low, which results in a slower rearrangement of ferrihydrite particles allowing for the dissolution of ferrihydrite and reprecipitation as goethite.

Our results show that once goethite started forming on the overhead stirrer, magnetite generation was inhibited. This is evident from comparison of the amount of magnetite generated at $16 \mathrm{~h}, 2$, and 4 days (Fig. 3). Magnetite inhibition was explained by Tufano et al. (2009) as being due to the removal of tetrahedral $\mathrm{Fe}$ (III) centers in ferrihydrite that are presumed to be necessary for the $\mathrm{Fe}$ (II)induced nucleation of magnetite. Magnetite has an inverse spinel structure with $\mathrm{Fe}(\mathrm{II})$ atoms in the octahedral positions and $\mathrm{Fe}$ (III) atoms both at the tetrahedral and octahedral positions (Cornell and Schwertmann 2003). Hence, tetrahedral $\mathrm{Fe}(\mathrm{III})$ centers in ferrihydrite could help lower 


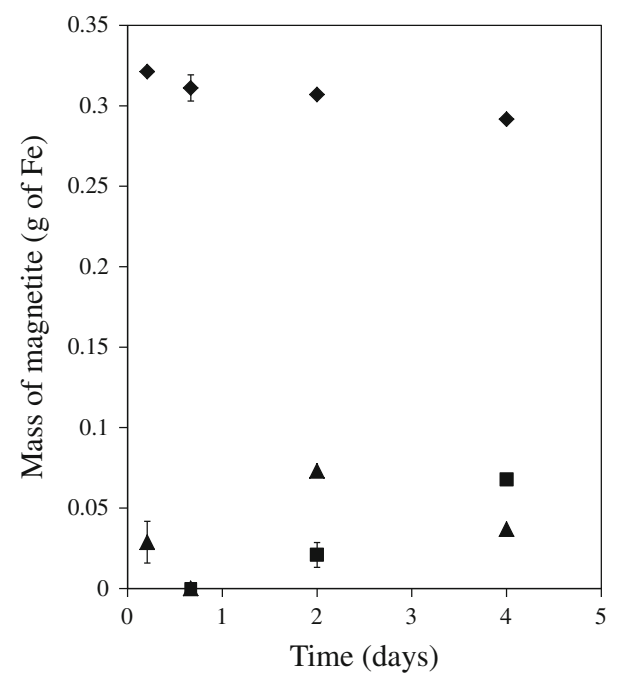

Fig. 3 Magnetite generated as a function of time using a magnetic stirrer (diamond), overhead stirrer (square), and an overhead stirrer with a magnetic bead attached to the propeller shaft (triangle). Conditions as in Figs. 1 and 2

the free energy required for magnetite nucleation in the presence of $\mathrm{Fe}(\mathrm{II})$. But the presence of tetrahedral $\mathrm{Fe}$ (III) in ferrihydrite is still an unresolved issue, with more evidence mounting against it (Rancourt and Meunier, 2008, Manceau 2009, 2011, 2012). Hence, the reason for the observed inhibition of magnetite generation in our study once goethite formation started is still unclear.

The relative amounts of ZVI and magnetite in experiments on both the magnetic and overhead stirrer in our study were determined using the ZVI-magnetite quantification technique described in the "Materials and methods" section. In the magnetically stirred system, the possibility of any untransformed ferrihydrite remaining in the system was ruled out using a magnetic bead to separate the magnetic and nonmagnetic fractions. After separation, there was no residual nonmagnetic fraction remaining. In the case of the overhead stirrer, the nonmagnetic fraction was significant. The objective behind quantifying the amounts of magnetite and ZVI was to elucidate the relative importance of the different operative mechanisms. In other words, it was to quantitatively demonstrate the differences between the amount of magnetite formed and the amount of ZVI consumed in the two systems employing the overhead and magnetic stirrer.

In order to test the hypothesis that high local $\mathrm{Fe}^{2+}$ concentrations were responsible for the differences in the transformation products in the two systems, experiments were performed in the overhead stirrer system as well as the magnetic stirrer system by adding a ferrous sulfate solution directly, instead of using ZVI as a source of $\mathrm{Fe}^{2+}$. In these trials, the objective was to approximate the $\mathrm{Fe}^{2+}$ generation rates observed in the magnetic and overhead stirrer systems when ZVI was used as the $\mathrm{Fe}^{2+}$ source, but to do so without ZVI present (and hence determine if the presence of ZVI solid, per se, was a significant factor). The rates of $\mathrm{Fe}^{2+}$ generation in the two systems were calculated from the rates of ZVI consumption. These were in turn estimated using the ZVI-magnetite quantification procedure (described above) to determine the amount of $\mathrm{ZVI}$ consumed over different time periods. It was determined that $0.15 \mathrm{~g}$ of $\mathrm{Fe}^{2+}$ was generated in the magnetic stirrer system in $5 \mathrm{~h}$, and from the XRD spectra and ZVI-magnetite quantification, it was confirmed that all the ferrihydrite solid was transformed into magnetite within this period. Similarly, it was determined that $0.3 \mathrm{~g}$ of $\mathrm{Fe}^{2+}$ was generated in the overhead stirrer system in 4 days, while the ferrihydrite started transforming into both magnetite and goethite.

A syringe pump was used to supply $\mathrm{Fe}^{2+}$ at two different rates-a faster rate $\left(30.6 \mathrm{mg}\right.$ of $\mathrm{Fe}^{2+} / \mathrm{hr}$ for $\left.5 \mathrm{~h}\right)$ to mimic $\mathrm{Fe}^{2+}$ generation from ZVI on the magnetic stirrer, and a slower rate $\left(3.1 \mathrm{mg}\right.$ of $\mathrm{Fe}^{2+} / \mathrm{hr}$ for 4 days) to mimic that on the overhead stirrer. Experiments at both rates were performed in the magnetic stirrer system as well as in the overhead stirrer system.

XRD analysis of the products (Fig. 4) showed that the faster inflow rate of $\mathrm{Fe}^{2+}$ yielded magnetite in both systems, whereas the experiments with the slower inflow rate of $\mathrm{Fe}^{2+}$ resulted in no transformation of ferrihydrite to goethite or magnetite (no crystalline solid products were detected by XRD) in either system. In one replicate experiment with the magnetic stirrer and the slow $\mathrm{Fe}^{2+}$ supply rate, weak peaks for goethite were detected, indicating that small amounts of goethite were being formed. It is not clear why no ferrihydrite transformation to goethite was observed within 4 days as had been observed on the overhead stirrer when ZVI was used as the source of $\mathrm{Fe}^{2+}$. One explanation could be that the estimates for $\mathrm{Fe}^{2+}$ inflow rate were based on the amount of ZVI consumed in 4 days on the overhead stirrer assuming a linear rate for $\mathrm{Fe}^{2+}$ generation over this period. This is a likely simplification of the actual $\mathrm{Fe}^{2+}$ generation rate on the overhead stirrer throughout the reaction time, as the rate was more likely faster during the initial stages of the experiment and slowed down once magnetite and goethite generation began, due to passivation of the ZVI surface. A detailed kinetic study of the rate of $\mathrm{Fe}^{2+}$ generation from ZVI was not the focus of this study and hence was not undertaken to test the degree to which the rate was nonlinear. Nevertheless, these experiments do prove that at a faster inflow rate of $\mathrm{Fe}^{2+}$ and consequently higher $\mathrm{Fe}^{2+}$ concentrations, magnetite is the only product formed, irrespective of whether the overhead stirrer or the magnetic stir plate was used, thus 


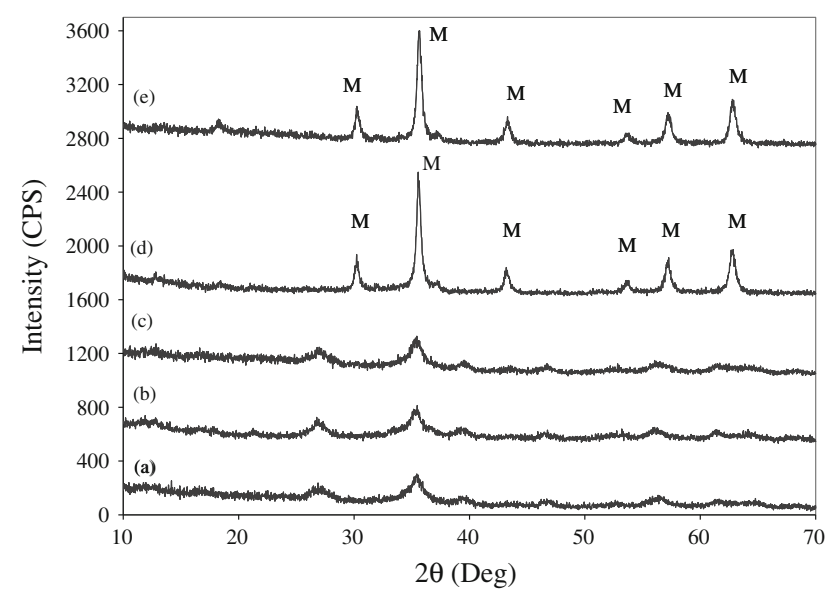

Fig. 4 XRD spectra for initial ferrihydrite $(a)$; solid products of ferrihydrite transformation when $\mathrm{Fe}^{2+}$ was added: at $3.13 \mathrm{mg}$ of $\mathrm{Fe}^{2+}$ / hr for 4 days on the magnetic stir plate $(b)$; at $3.13 \mathrm{mg}$ of $\mathrm{Fe}^{2+} / \mathrm{hr}$ for 4 days on the overhead stirrer (c); at $30.61 \mathrm{mg}$ of $\mathrm{Fe}^{2+} / \mathrm{hr}$ for $5 \mathrm{~h}$ on the magnetic stir plate $(d)$; and at $30.61 \mathrm{mg}$ of $\mathrm{Fe}^{2+} / \mathrm{hr}$ for $5 \mathrm{~h}$ on the overhead stirrer $(e)$

also negating the presence/absence of a magnetic field being a significant determinant.

In the case of the magnetically stirred system, mechanical abrasion/grinding of the ZVI particles between the magnetic bead surface and the vessel bottom could help keep the ZVI surface clean, hence maintaining its surface reactivity, and leading to a relatively high rate of $\mathrm{Fe}^{2+}$ generation. An experiment was setup in the overhead stirrer system with a magnetic bead attached to the propeller shaft of the stirrer to examine the importance of this mechanism in explaining the observed phenomena. This was expected to create localized high $\mathrm{Fe}^{2+}$ concentrations, while excluding any abrasion effects. Individual batch trials were setup and once again killed after $16 \mathrm{~h}, 3$, and 10 days. The XRD spectra of the 10-day long experiment are shown in Fig. 5. It is clear that the products after 10 days in the overhead stirrer system with a magnetic bead attached to the propeller are goethite and magnetite, which replicates results without the magnetic bead attached to the propeller. This was contrary to our expectation, which assumed high local $\mathrm{Fe}^{2+}$ concentrations would be present at the magnetic surface and that magnetite would be the only product. It was confirmed that all the ZVI particles stay on the bead and do not shear off during mixing by the overhead stirrer, via visual observation in a system where ZVI was added in the absence of ferrihydrite. An explanation for this unexpected result could be that when ZVI is used as a source of $\mathrm{Fe}^{2+}$ the creation of high local $\mathrm{Fe}^{2+}$ concentrations depended on the presence of abrasion to maintain the surface reactivity of the ZVI surface.

Mechanical abrasion may thus play an indirect role in pre-disposing the ferrihydrite-ZVI system to form

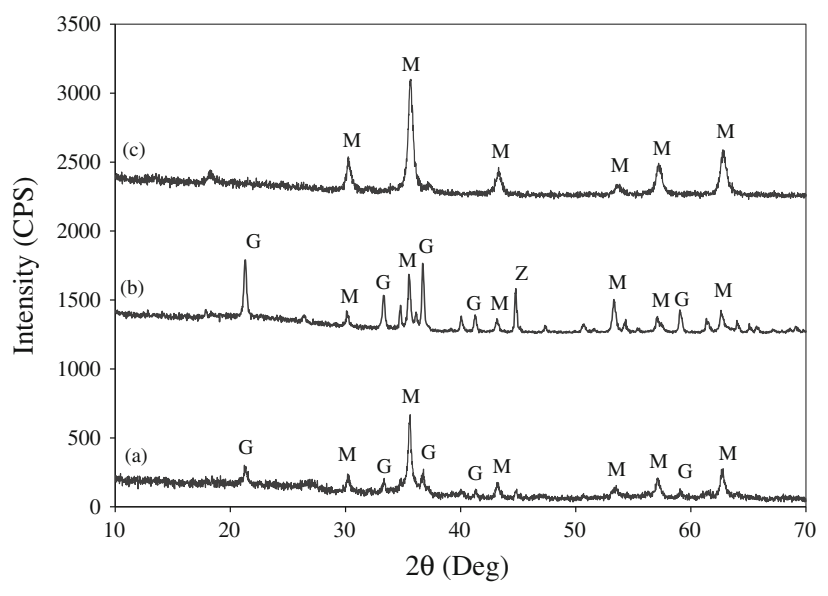

Fig. 5 XRD spectra for solid products of ferrihydrite transformation in the presence of ZVI on: overhead stirrer with a magnetic bead attached to the propeller $(a)$; overhead stirrer without any magnetic bead attached $(b)$; and magnetic stir plate $(c)$. All experiments were performed with an initial $\mathrm{Fe}(\mathrm{III})$ :ZVI ratio of 1.0 and an initial $\mathrm{pH}$ of $6.8 \pm 0.2$

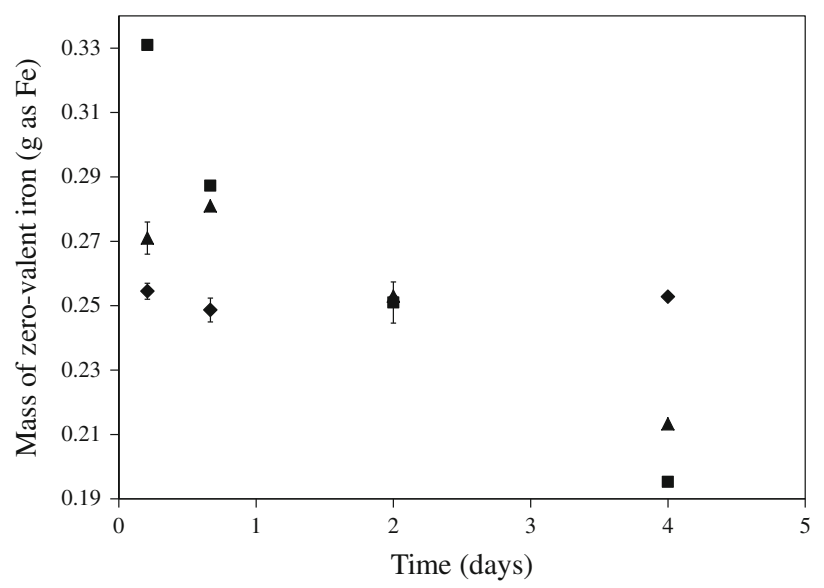

Fig. 6 Zero-valent iron remaining as a function of time using a magnetic stirrer (diamond), an overhead stirrer (square), and an overhead stirrer with a magnetic bead attached to the propeller shaft (triangle). Initial amount of ZVI added to each system $=0.3 \mathrm{~g}$. The 2-day data points for all three systems overlap with each other

magnetite by allowing the creation of high local $\mathrm{Fe}^{2+}$ concentrations. To confirm this, we compared the amount of ZVI remaining after different time periods on the magnetic stir plate, overhead stirrer, and the overhead stirrer with the magnetic bead attached to the propeller (Fig. 6). We observed rapid consumption of ZVI on the magnetic stirrer initially, and then the amount of ZVI stayed constant in the system.

In contrast, the ZVI consumption rate is much slower in the case of the overhead stirrer both with and without the magnetic bead attached to the propeller. We also observed 
that ZVI consumption continues for 4 days of the experiment, whereas in the case of the magnetic stirrer, the ZVI consumption stopped after $5 \mathrm{~h}$. The initial rapid consumption of the ZVI on the magnetic stir plate is consistent with mechanical abrasion maintaining the surface reactivity of ZVI in this system.

An experiment was conducted to test the possibility that the presence of a magnetic field predisposes the ferrihydrite toward transforming to magnetite. A magnetic stir plate was placed underneath the beaker containing the same amounts of ferrihydrite and ZVI as described earlier. The magnetic stir plate was kept turned on but at zero rpm so that there was no motion/abrasion of the zero-valent particles, while still ensuring the presence of a magnetic field. An overhead stirrer (at $300 \mathrm{rpm}$ ) was used to mix the suspension. All other initial parameters were maintained the same as described previously. Upon separating out the magnetic fraction and performing the ZVI-magnetite quantification procedure, the amount of magnetite formed in this system (not shown) was found to be insignificant compared with that formed on the magnetic stir plate. Hence, the presence of a magnetic field was eliminated as an important mechanism in the context of the objectives of this study. It should be noted that it was not the authors' objective to gain quantitative insights into effects of the intensity of the magnetic field on ferrihydrite transformation pathways/products, but rather to test whether the magnetic field generated by the magnetic stirrer may lead the ferrihydrite-ZVI system toward the observed transformation pathways/products.

Another factor considered was whether the presence of nucleation sites (in this case the ZVI particles) co-located with the high $\mathrm{Fe}^{2+}$ concentrations was necessary for magnetite formation. The ZVI particles would act not only as a source of ferrous ions but also as potential nucleation sites for the formation of magnetite particles. Since ZVI is the main source of $\mathrm{Fe}^{2+}$ in our experiments-it was difficult to unequivocally delineate surface effects from $\mathrm{Fe}^{2+}$ concentration effects. However, from the experiments with direct $\mathrm{Fe}^{2+}$ addition it is evident that when high $\mathrm{Fe}^{2+}$ concentrations are present, a crystalline surface (i.e., ZVI particles) is not required in order to dispose the system to form magnetite.

Other researchers have observed the transformation of ferrihydrite to magnetite due to the presence of high local concentrations of an electron donor. Burton et al. (2011) observed the transformation of As(III)-bearing ferrihydritecoated quartz sand to mackinawite, magnetite and goethite after 28 days of advective-flow column experiments. The columns were inoculated with Desulfovibrio vulgaris, a sulfate reducer. It was observed that magnetite formation was dominant near the influent end of the columns where

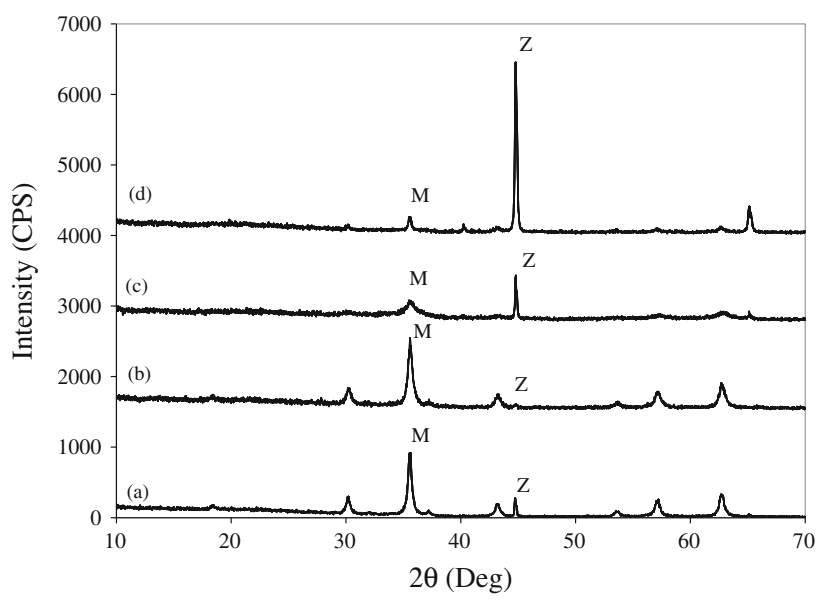

Fig. 7 XRD spectra for solid products of iron-arsenic solid transformation in the presence of ZVI on the magnetic stirrer. Solids with the following Fe/As ratios were used: (a) ferrihydrite with no arsenic, (b) $\mathrm{Fe} / \mathrm{As}=100,(c) \mathrm{Fe} / \mathrm{As}=20$, and $(d) \mathrm{Fe} / \mathrm{As}=5.7$. All experiments were performed with an initial $\mathrm{Fe}(\mathrm{III}): \mathrm{ZVI}$ ratio of 1.0 and an initial $\mathrm{pH}$ of $6.8 \pm 0.2$. M-100 \% peak for magnetite, Z-100 \% peak for zero-valent iron

intense sulfidogenesis was happening. This was explained as being due to the presence of high sulfide concentrations locally near the inflow end of the column resulting in high electron current density needed for the solid-state transformation of ferrihydrite to magnetite. We think that in our study, the high local concentrations of $\mathrm{Fe}^{2+}$ that would be generated due to the localization of the electron donor (ZVI in this case) on the magnetic bead in the magnetically stirred system resulted in the transformation of ferrihydrite to magnetite.

Experiments to study the effect of arsenic's presence on the transformation of amorphous ferric hydroxide at relatively high local $\mathrm{Fe}^{2+}$ concentrations were performed only in the magnetic stirrer system since the objective was to see if the presence of arsenic inhibited the ferrihydrite transformation to magnetite. The XRD spectra (Fig. 7) of final solid products from these experiments indicated that magnetite was formed in all three systems, but the peaks for magnetite were progressively weaker as the $\mathrm{Fe} / \mathrm{As}$ ratio in the original solid was decreased from $\mathrm{Fe} / \mathrm{As}=100$ to $\mathrm{Fe} / \mathrm{As}=20$ and $\mathrm{Fe} / \mathrm{As}=5.7$. Only a trace amount of magnetite formed in the latter case (Fig. 7). The peaks for ZVI showed the opposite trend. Despite the fact that XRD results are qualitative, the relative amplitudes of ZVI and magnetite determined from the XRD peaks are 22:6:1 and 1:1:3 written as respective fractions in experiments with $\mathrm{Fe} / \mathrm{As}=5.7: \mathrm{Fe} / \mathrm{As}=20: \mathrm{Fe} / \mathrm{As}=100$. This clearly indicates variations in the relative amounts of the two minerals. This result is consistent with observations from other studies that found that the presence of arsenic limits the transformation of ferrihydrite to magnetite (Kocar et al. 2006; Herbel and Fendorf 2006). Kocar et al. 2006 used 


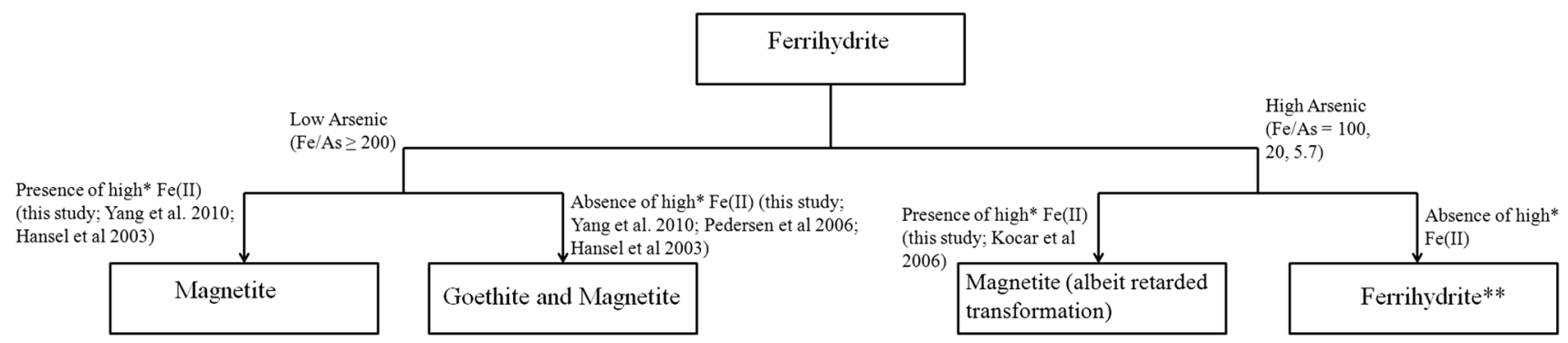

Fig. 8 Summary of transformation pathways of amorphous ferric hydroxide under different arsenic loadings and presence/absence of high $\mathrm{Fe}(\mathrm{II})$ concentrations. ${ }^{*}$ High $\mathrm{Fe}^{2+}$ concentrations can either be localized (this study) or uniformly distributed (other studies). Hansel et al. (2003) observed that a threshold Fe(II) concentration level of $0.3 \mathrm{mM}$ is required for magnetite nucleation. ${ }^{* *}$ Suggested/presumed short-term mineralogy (not confirmed in this study). Presence of high

biotic columns loaded with As (V)-bearing ferrihydrite to study arsenic elution. Secondary mineral formation showed partial transformation of ferrihydrite to magnetite. The columns were inoculated with Shewanella putrefaciens, an organism capable of reducing both $\mathrm{Fe}(\mathrm{III})$ and $\mathrm{As}(\mathrm{V})$ and had arsenic loadings ( $\mathrm{Fe} / \mathrm{As}=22$ and 111) similar to the ones used in this study. The highest level of transformation to magnetite in all these columns was observed near the outlet of the columns (at around $15 \mathrm{~cm}$ from the inlet in a 20-cm long column). Dominant iron mineralogy from Extended X-ray absorption fine spectra (EXAFS) measurements at this section of the columns in the Kocar et al. 2006 study indicated $\sim 9$ mol \% magnetite after 25 days in the columns loaded with $\mathrm{As}(\mathrm{V})$-bearing ferrihydrite, as opposed to $59 \mathrm{~mol} \%$ magnetite after 16 days of reaction in the columns loaded with ferrihydrite but no arsenic. The level of transformation to magnetite, though much lower than that observed in similar columns without any arsenic, was still appreciable (Hansel et al. 2003). Ferrihydrite transformation to goethite was not observed in any of their columns loaded with arsenic even though goethite was a major transformation product in similar columns with no arsenic. Pedersen et al. (2006) studied the effect of low arsenic concentrations on iron oxide transformations. They observed no inhibition of ferrihydrite transformation to goethite at low arsenic loadings (Fe/As $\geq 200$ ). A flowchart summarizing the transformation products of ferrihydrite under different arsenic loadings and $\mathrm{Fe}^{2+}$ concentrations (observed in this and other studies) is shown in Fig 8.

\section{Conclusion}

This study looked at the differences in ferrihydrite transformation pathways caused by differences in local $\mathrm{Fe}^{2+}$ arsenic concentrations inhibit transformation of ferrihydrite to goethite by interfering with both the dissolution of ferrihydrite and the re-precipitation of goethite. Long-term arsenic sequestration/ release will depend on the relative rates of ferrihydrite dissolution and re-precipitation as goethite in the presence of high concentrations of arsenic

concentration. When magnetic solids (i.e., ZVI, magnetite) are concentrated on a magnetic stir bar rather than dispersed throughout the fluid, magnetite was the sole product of the ferrihydrite/ZVI system. In contrast, both goethite and magnetite were detected when an overhead stirrer was employed for mixing. Various mechanisms were considered to explain the observed differences between the two systems - the presence or absence of localized high $\mathrm{Fe}^{2+}$ concentrations, mechanical abrasion/grinding effects on the ZVI particles, role of ZVI particles as nucleation sites for magnetite synthesis, and the presence/absence of a magnetic field.

In the system studied, high $\mathrm{Fe}^{2+}$ concentrations could only be obtained if the $\mathrm{Fe}^{2+}$ source (ZVI) was locally concentrated (i.e., on a magnetic stir bar) and the ZVI surface was refreshed by abrasion. This study confirmed that the presence of high local $\mathrm{Fe}^{2+}$ concentrations caused ferrihydrite transformation to magnetite. Preliminary experiments with ZVI and three different $\mathrm{Fe} / \mathrm{As}$ ratios showed that the amount of magnetite formed decreased with increasing loading of arsenic. Lower arsenic loadings of $\mathrm{Fe} / \mathrm{As}=100$ and $\mathrm{Fe} / \mathrm{As}=20$, which are more representative of the loadings achieved in actual ABSRs generated after water treatment, still showed significant transformation to magnetite.

These findings have implications for arsenic release in natural systems and landfills. Arsenic is ubiquitously associated with iron (hydr)oxides in natural systems, and the residuals generated from arsenic removal processes in water treatments systems. Iron oxide transformations (both biotic and abiotic) have been studied and reported to have significant implications for the leachability and mobility of arsenic in natural aquatic systems and landfills (Ghosh et al. 2006; Cortinas et al. 2008; Stuckman et al. 2011; Wang et al. 2012; Root et al. 2013). The possible transformations that the iron minerals undergo may determine 
the ultimate stability of the associated arsenic owing to differences in their arsenic retention capacities. Spatial heterogeneity in the distribution of iron oxides, microbes and/or reducing agents in soils can result in locally high $\mathrm{Fe}^{2+}$ concentrations. The findings from this study show that local $\mathrm{Fe}^{2+}$ concentrations can pre-dispose ferrihydrite to transform into magnetite or goethite. These minerals have different sequestration capacities for arsenic due to differences in their surface areas and sorption affinities for arsenic species.

Recent X-ray absorption spectroscopy (XAS) and Fourier transform infrared spectroscopy (FT-IR) studies have reported that arsenic sequestration in an iron oxide is due (but not limited) to the following mechanisms: coprecipitation, adsorption by the formation of surface precipitates, and/or formation of inner- and outer-sphere complexes (Wang et al. 2008; Morin et al. 2009; Müller et al. 2010; Wang et al. 2011). The mode of arsenic sequestration/incorporation is different for different minerals. For instance, it has been observed that $\mathrm{As}(\mathrm{V})$ can be incorporated within the magnetite structure during co-precipitation experiments (Wang et al. 2011; Coker et al. 2006). Wang et al. (2011) demonstrated that during the $\mathrm{Fe}(\mathrm{II})$-induced transformation of $\mathrm{As}(\mathrm{V})$-sorbed lepidocrocite to magnetite, arsenate tetrahedra were incorporated within magnetite nanoparticles with increasing loading of arsenic. Such a trapping mechanism for arsenate has not yet been established with sufficient spectroscopic evidence in the case of goethite. The mode of association of the arsenic with an iron oxide is expected to have a significant influence on the fate and mobility of the associated arsenic. Thus, local $\mathrm{Fe}^{2+}$ concentrations can have significant implications for the sequestration or release of arsenic by determining the transformation products of ferrihydrite under reducing conditions.

Acknowledgments This work was supported by the National Institute of Environmental Health Sciences (NIEHS) Grant No. P42 ES04940. The authors declare that they have no conflict of interest. This paper's contents are solely the responsibility of the authors and do not necessarily represent the official views of NIEHS. The authors wish to thank Phil Anderson of the University Spectroscopic Imaging Facility at the University of Arizona for performing the XRD analyses. The authors also wish to acknowledge the work of an undergraduate student, I-Tso Chen, who assisted with sample preparation for XRD analysis, and microwave digestions for aqueous iron analysis.

\section{REFERENCES}

Benner S, Hansel C, Wielinga B, Barber T, Fendorf S (2002) Reductive dissolution and biomineralization of iron hydroxide under dynamic flow conditions. Environ Sci Technol $36: 1705-1711$
Burnol A, Charlet L (2010) Fe(II)-Fe(III)-bearing phases as a mineralogical control on the heterogeneity of arsenic in Southeast Asian groundwater. Environ Sci Technol 44:7541-7547

Burnol A, Garrido F, Baranger P, Joulian C, Dictor M, Bodenan F et al (2007) Decoupling of arsenic and iron release from ferrihydrite suspension under reducing conditions: a biogeochemical model. Geochem Trans. doi:10.1186/1467-4866-8-12

Burton ED, Johnston SG, Bush RT (2011) Microbial sulfidogenesis in ferrihydrite-rich environments: effects on iron mineralogy and arsenic mobility. Geochim Cosmochim Acta 75:3072-3087

Clesceri LS, Greenberg AE, Eaton AD (1998) Standard Methods for the Examination of Water and Wastewater. APHA, Washington DC

Coker VS, Gault AG, Pearce CI, van der Laan G, Telling ND, Charnock JM et al (2006) XAS and XMCD evidence for speciesdependent partitioning of arsenic during microbial reduction of ferrihydrite to magnetite. Environ Sci Technol 40:7745-7750

Cornell R (1988) The influence of some divalent-cations on the transformation of ferrihydrite to more crystalline products. Clay Miner 23:329-332

Cornell RM, Schwertmann U (2003) The Iron Oxides: Structure, Properties, Reactions. Occurences and Uses, Wiley VCH

Cortinas I, Sierra-Alvarez R, Field JA (2008) Biologically mediated mobilization of arsenic from granular ferric hydroxide in anaerobic columns fed landfill leachate. Biotechnol Bioeng 101:1205-1213

Das S, Hendry MJ, Essilfie-Dughan J (2011a) Effects of adsorbed arsenate on the rate of transformation of 2-line ferrihydrite at $\mathrm{pH}$ 10. Environ Sci Technol 45:5557-5563

Das D, Hendry MJ, Essilfie-Dughan J (2011b) Transformation of twoline ferrihydrite to goethite and hematite as a function of $\mathrm{pH}$ and temperature. Environ Sci Technol 45:268-275

Datta S, Mailloux B, Jung HB, Hoque MA, Stute M, Ahmed KM, Zheng Y (2009) Redox trapping of arsenic during groundwater discharge in sediments from the Meghna riverbank in Bangladesh. Proc Natl Acad Sci USA 106:16930-16935

Dixit S, Hering J (2003) Comparison of arsenic(V) and arsenic(III) sorption onto iron oxide minerals: implications for arsenic mobility. Environ Sci Technol 37:4182-4189

Ghosh A, Mukiibi M, Saez AE, Ela WP (2006) Leaching of arsenic from granular ferric hydroxide residuals under mature landfill conditions. Environ Sci Technol 40:6070-6075

Giles DE, Mohapatra M, Issa TB, Anand S, Singh P (2011) Iron and aluminum based adsorption strategies for removing arsenic from water. J Environ Manage 92:3011-3022

Halim MA, Majumder RK, Nessa SA, Oda K, Hiroshiro Y, Jinno K (2010) Arsenic in shallow aquifer in the eastern region of Bangladesh: insights from principal component analysis of groundwater compositions. Environ Monit Assess 161:453-472

Hansel C, Benner S, Neiss J, Dohnalkova A, Kukkadapu R, Fendorf S (2003) Secondary mineralization pathways induced by dissimilatory iron reduction of ferrihydrite under advective flow. Geochim Cosmochim Acta 67:2977-2992

Hansel C, Benner S, Fendorf S (2005) Competing Fe(II)-induced mineralization pathways of ferrihydrite. Environ Sci Technol 39:7147-7153

Herbel M, Fendorf S (2006) Biogeochemical processes controlling the speciation and transport of arsenic within iron coated sands. Chem Geol 228:16-32

Horneman A, Van Geen A, Kent D, Mathe P, Zheng Y, Dhar R et al (2004) Decoupling of As and $\mathrm{Fe}$ release to Bangladesh groundwater under reducing conditions. Part 1: evidence from sediment profiles. Geochim Cosmochim Acta 68:3459-3473

Islam F, Gault A, Boothman C, Polya D, Charnock J, Chatterjee D et al (2004) Role of metal-reducing bacteria in arsenic release from Bengal delta sediments. Nature 430:68-71 
Jekel M, Amy JL (2006) Chapter 11: Arsenic removal during drinking water treatment. In: Newcombe G and Dixon D (eds) Interface Science in Drinking Water Treatment, 1st edn. Elsevier

Jing C, Liu S, Meng X (2008) Arsenic remobilization in water treatment adsorbents under reducing conditions: part I incubation study. Sci Total Environ 389:188-194

Kocar BD, Herbel MJ, Tufano KJ, Fendorf S (2006) Contrasting effects of dissimilatory iron(III) and $\operatorname{arsenic}(\mathrm{V})$ reduction on arsenic retention and transport. Environ Sci Technol 40:6715-6721

Latta DE, Gorski CA, Scherer MM (2012) Influence of Fe(2+)catalyzed iron oxide recrystallization on metal cycling. Biochem Soc Trans 40:1191-1197

Liu H, Wei Y, Sun Y, Wei W (2005) Dependence of the mechanism of phase transformation of $\mathrm{Fe}$ (III) hydroxide on $\mathrm{pH}$. Colloids Surf A Physicochem Eng Asp 252:201-205

Liu H, Guo H, Li P, Wei Y (2008a) The transformation of ferrihydrite in the presence of trace $\mathrm{Fe}(\mathrm{II})$ : the effect of the anionic media. J Solid State Chem 181:2666-2671

Liu S, Jing C, Meng X (2008b) Arsenic re-mobilization in water treatment adsorbents, under reducing conditions: part II. XAS and modeling study. Sci Total Environ 392:137-144

Maity JP, Nath B, Chen CY, Bhattacharya P, Sracek O, Bundschuh J, Kar S, Thunvik R, Chatterjee D, Ahmed KM, Jacks G, Mukherjee AB, Jean JS (2011) Arsenic-enriched groundwaters of India, Bangladesh and Taiwan-comparison of hydrochemical characteristics and mobility constraints. J Environ Sci Health A Tox Hazard Subst Environ Eng 46:1163-1176

Mamindy-Pajany Y, Hurel C, Marmier N, Romeo M (2011) Arsenic (V) adsorption from aqueous solution onto goethite, hematite, magnetite and zero-valent iron: effects of $\mathrm{pH}$, concentration and reversibility. Desalination 281:93-99

Manceau A (2009) Evaluation of the structural model for ferrihydrite derived from real-space modelling of high-energy X-ray diffraction data. Clay Miner 44:19-34

Manceau A (2011) Critical evaluation of the revised akdalaite model for ferrihydrite. Am Mineral 96:521-533

Manceau A (2012) Comment on "direct observation of tetrahedrally coordinated $\mathrm{Fe}(\mathrm{III})$ in ferrihydrite". Environ Sci Technol 46:6882-6884

Masue-Slowey Y, Ying SC, Kocar BD, Pallud CE, Fendorf S (2013) Dependence of arsenic fate and transport on biogeochemical heterogeneity arising from the physical structure of soils and sediments. J Environ Qual 42:1119-1129

Morin G, Wang Y, Ona-Nguema G, Juillot F, Calas G, Menguy N et al (2009) EXAFS and HRTEM evidence for As(III)-containing surface precipitates on nanocrystalline magnetite: implications for As sequestration. Langmuir 25:9119-9128

Mukiibi M, Ela WP, Sáez AE (2008) Effect of ferrous iron on arsenate sorption to amorphous ferric hydroxide. Ann NY Acad Sci 1140:335-345

Müller K, Ciminelli VS, Dantas MS, Willscher S (2010) A comparative study of $\mathrm{As}(\mathrm{III})$ and $\mathrm{As}(\mathrm{V})$ in aqueous solutions and adsorbed on iron oxy-hydroxides by Raman spectroscopy. Water Res 44:5660-5672

Neumann A, Kaegi R, Voegelin A, Hussam A, Munir AK, Hug SJ (2013) Arsenic removal with composite iron matrix filters in Bangladesh: a field and laboratory study. Environ Sci Technol 47:4544-4754

Nguyen KP, Itoi R (2009) Source and release mechanism of arsenic in aquifers of the Mekong delta Vietnam. J Contam Hydrol 103:58-69

O'Loughlin EJ, Gorski CA, Scherer MM, Boyanov MI, Kemner KM (2010) Effects of oxyanions, natural organic matter, and bacterial cell numbers on the bioreduction of lepidocrocite
(gamma-FeOOH) and the formation of secondary mineralization products. Environ Sci Technol 44:4570-4576

Omoregie EO, Couture RM, Van Cappellen P, Corkhill CL, Charnock JM, Polya DA, Vaughan D, Vanbroekhoven K, Lloyd JR (2013) Arsenic bioremediation by biogenic iron oxides and sulfides. Appl Environ Microbiol 79:4325-4335

Pallud C, Masue-Slowey Y, Fendorf S (2010) Aggregate-scale spatial heterogeneity in reductive transformation of ferrihydrite resulting from coupled biogeochemical and physical processes. Geochim Cosmochim Acta 74:2811-2825

Pedersen H, Postma D, Jakobsen R, Larsen O (2005) Fast transformation of iron oxyhydroxides by the catalytic action of aqueous Fe(II). Geochim Cosmochim Acta 69:3967-3977

Pedersen HD, Postma D, Jakobsen R (2006) Release of arsenic associated with the reduction and transformation of iron oxides. Geochim Cosmochim Acta 70:4116-4129

Rancourt DG, Meunier J- (2008) Constraints on structural models of ferrihydrite as a nanocrystalline material. Am Mineral 93:1412-1417

Reza AH, Jean JS, Lee MK, Liu CC, Bundschuh J, Yang HJ, Lee JF, Lee YC (2010) Implications of organic matter on arsenic mobilization into groundwater: evidence from northwestern (Chapai-Nawabganj), central (Manikganj) and southeastern (Chandpur) Bangladesh. Water Res 44:5556-5574

Root RA, Fathordoobadi S, Alday F, Ela W, Chorover J (2013) Microscale speciation of arsenic and iron in ferric-based sorbents subjected to simulated landfill conditions. Environ Sci Technol 47:12992-13000

Schwertmann U, Cornell RM (1991) Iron Oxides in the Laboratory: Preparation and Characterization. VCH, New York, pp 111-113

Shan H, Ma T, Wang Y, Zhao J, Han H, Deng Y, He X, Dong Y (2013) A cost-effective system for in situ geological arsenic adsorption from groundwater. J Contam Hydrol 154:1-9

Smedley P, Kinniburgh D (2002) A review of the source, behaviour and distribution of arsenic in natural waters. Appl Geochem 17:517-568

Stuckman MY, Lenhart JJ, Walker HW (2011) Abiotic properties of landfill leachate controlling arsenic release from drinking water adsorbents. Water Res 45:4782-4792

Tronc E, Belleville P, Jolivet J, Livage J (1992) Transformation of ferric hydroxide into spinel by Fe(II) adsorption. Langmuir 8:313-319

Tufano KJ, Fendorf S (2008) Confounding impacts of iron reduction on arsenic retention. Environ Sci Technol 42:4777-4783

Tufano KJ, Benner SG, Mayer KU, Marcus MA, Nico PS, Fendorf S (2009) Aggregate-scale heterogeneity in iron (Hydr)oxide reductive transformations. Vadose Zone J 8:1004-1012

van Geen A, Zheng Y, Cheng Z, Aziz Z, Horneman A, Dhar R et al (2006) A transect of groundwater and sediment properties in Araihazar, Bangladesh: further evidence of decoupling between As and Fe mobilization. Chem Geol 228:85-96

Wang Y, Morin G, Ona-Nguema G, Menguy N, Juillot F, Aubry E et al (2008) Arsenite sorption at the magnetite-water interface during aqueous precipitation of magnetite: eXAFS evidence for a new arsenite surface complex. Geochim Cosmochim Acta $72: 2573-2586$

Wang Y, Morin G, Ona-Nguema G, Juillot F, Calas G, Brown GE Jr (2011) Distinctive arsenic(V) trapping modes by magnetite nanoparticles induced by different sorption processes. Environ Sci Technol 45:7258-7266

Wang Y, Sikora S, Kim H, Dubey B, Townsend T (2012) Mobilization of iron and arsenic from soil by construction and demolition debris landfill leachate. Waste Manag 32:925-932 
Yang L, Steefel CI, Marcus MA, Bargar JR (2010) Kinetics of Fe(II)catalyzed transformation of 6-line ferrihydrite under anaerobic flow conditions. Environ Sci Technol 44:5469-5475

Yee N, Shaw S, Benning L, Nguyen T (2006) The rate of ferrihydrite transformation to goethite via the $\mathrm{Fe}(\mathrm{II})$ pathway. Am Mineral 91:92-96
Zegeye A, Mustin C, Jorand F (2010) Bacterial and iron oxide aggregates mediate secondary iron mineral formation: green rust versus magnetite. Geobiology 8:209-222 